\title{
An Exploratory Analysis of the Representations of Functions in the University Entrance Exam in Spain and Iran
}

\author{
Vahid Borji ${ }^{1,2^{*}}$, Alicia Sánchez ${ }^{1}$ \\ ${ }^{1}$ Department of Linguistic and Literary Education, and Teaching and Learning of Experimental Sciences and Mathematics, \\ University of Barcelona, Catalonia, SPAIN \\ ${ }^{2}$ Department of Applied Mathematics, Faculty of Mathematical Sciences, Ferdowsi University of Mashhad, IRAN
}

Received 30 October 2018 - Revised 22 January 2019 • Accepted 6 February 2019

\begin{abstract}
The University Entrance Exam (UEE) has an important impact on how math instructors teach mathematics to prepare students for this exam as well as how their students learn mathematics. Since the UEE is like a bridge between high school and university, its importance becomes twofold. However, research regarding this issue is very limited in mathematics education. The purpose of this research is to conduct an exploratory analysis of mathematics questions from the UEE in Spain and Iran from the point of view of representations of functions (i.e., algebraic, graphical, numerical and explanations with words). For this, the mathematics questions related to derivatives and integrals, which are two of the most important concepts in mathematics, from the last five years of the UEE in these two countries were considered to analyze them from the point of view of different representations. The results showed that most of the derivative and integral questions in the UEE in both countries were related to the algebraic representation. However, a very small percentage of the derivative and integral questions were related to the graphical and numerical representations and the relationships between the representations. At the end, suggestions to the curriculum planners and designers of mathematics questions of the UEEs are given.
\end{abstract}

Keywords: university entrance exam, mathematics questions, representations, derivative, integral

\section{INTRODUCTION}

In many countries, after graduating from high school, in order to enter university, students must take part in the University Entrance Exam (UEE) (Farrokhi-Khajeh-Pasha, et al., 2012; Kim \& Dembo, 2000; Koçkar \& Gençöz, 2004; Konečný, Basl, Mysliveček, \& Simonová, 2012; Kusayanagi, 2013; Zhang, 2016). Students need to get high marks in the UEE to get into popular universities and fields. The UEEs are very competitive, and a limited number of students can enter public universities each year. Topics/subjects covered in the UEE are topics/subjects that students have taken in the final years of high school. Depending on the field, the questions include mathematics, physics, chemistry, biology, etc. Students, in the last one or two years of high school, prepare themselves to participate in the UEE. Schools, institutions, and teachers also implement programs for the success of their students in the UEE. Many students, teachers, schools and educational institutions have got involved with the UEE. Sample questions of the previous years of the UEE are the sources that students refer to for problems to solve in order to be successful in the UEE.

Mathematics is one of the most important subjects that are included in the UEE (Koçkar \& Gençöz, 2004; Kusayanagi, 2013). Among the branches of Mathematics, the UEE has several questions about calculus, because of its importance both in high school and in university. Calculus questions of the UEE include concepts such as functions, limits, derivatives, and integrals.

(C) 2019 by the authors; licensee Modestum Ltd., UK. This article is an open access article distributed under the terms and conditions of the Creative Commons Attribution License (http://creativecommons.org/licenses/by/4.0/). \vborji@ub.edu vahid.borji65@gmail.com vahid.borji@mail.um.ac.ir (Correspondence) $\square$ asanchezb@ub.edu 


\section{Contribution of this paper to the literature}

- This article conducts an exploratory analysis of mathematics questions from the University Entrance Exam (UEE) in Spain and Iran from the point of view of representations of functions.

- The results showed that most of the derivative and integral questions in the UEE in both countries were related to the algebraic representation, and a very small percentage of the questions were related to the other representations and the relationships between them.

- Suggestions to the curriculum planners and designers of mathematics questions of the UEEs are given.

Many studies (Bolden, Barmby, \& Harries, 2013; Dreher \& Kuntze, 2015; Kendal, \& Stacey, 2003; Özmantar, Akkoç, Bingölbali, Demir, \& Ergene, 2010) have pointed to the importance of understanding a mathematical concept through various types of representations (i.e., algebraic, graphical and numerical). The use of different representations is also considered as an indicator of mathematical quality by many authors (Beltrán-Pellicer, Godino, \& Giacomone, 2018; Breda, Font, \& Pino-Fan, 2018; Breda, Pino-Fan, \& Font, 2017). Some researchers suggested that for students to achieve conceptual understanding of a mathematical concept, it might be better to learn that concept through a variety of representations and translations between those representations (Borji, Alamolhodaei, \& Radmehr, 2018; Ronda, 2015). In calculus education, translations from one representation to another one are recommended for achieving a deep understanding of concepts such as derivative and integral (Borji, Font, Alamolhodaei, \& Sánchez, 2018; Fuentealba, Sánchez-Matamoros, Badillo, \& Trigueros, 2017).

Some studies have shown that students in the first year of the university have difficulties with calculus concepts (Dominguez, Barniol, \& Zavala, 2017; Hardy, 2009). Calculus students usually have acceptable performance in solving routine questions that are represented algebraically (Baker, Cooley, \& Trigueros, 2000). Their difficulties begin when they see questions in the form of other representations, such as graphical and numerical representations (Baker, et al., 2000; Borji, Alamolhodaei, \& Radmehr, 2018; Sahin, Erbas, \& Yenmez, 2015). A number of students do not have a conceptual understanding of graphical and numerical representations of calculus concepts (Kendal \& Stacey 2003). Students in the first year of the university have difficulty in understanding the relationship between different representations of a mathematical concept (Borji, Font, Alamolhodaei, \& Sánchez, 2018; Dreher \& Kuntze, 2015). One of the reasons for these difficulties faced by students may be that they have not learned well the relationship between different representations of a calculus concept in the last years of high school (Mao, White, Sadler, \& Sonnert, 2017).

The importance of the UEE is very noticeable because it has a great impact on both the teaching of mathematics instructors and students' learning. However, research in relation to the UEE in Mathematics Education is very scarce. In this research, the mathematical questions related to the derivative and the integral of the last five years of the UEE in both Spain and Iran were examined from the point of view of representations (algebraic, graphical, numerical, and explanatory). This study aims to explore in which type of representations are the input information of mathematics questions in the UEE. The derivative and the integral questions were chosen because the UEE in both countries includes these two concepts.

The research question of this study is: How often the different representations appear in the mathematics questions of the UEE in Spain and Iran?

\section{THEORETICAL BACKGROUND}

In the theoretical background section, to frame this study, representations of mathematical concepts, the UEE in Spain and Iran, and the importance of the derivative and the integral concepts are described.

\section{Representations of Mathematical Concepts}

"The term representation refers both to process and to product" (National Council of Teachers of Mathematics, 2000, p. 67). As a process, it refers to making in one's mind a mental image of a mathematical concept. As a product, it refers to a physical form of that idea, such as a graph of a function, a symbolic expression, a table of numbers, or even explanations with words (Spangler, 2010). The idea of representation is important because the more ways a student can think about a mathematical concept, the better that student will learn the underlying mathematical concept (McAteer, 2012; Spangler, 2010).

“Instructional programs from prekindergarten through grade 12 should enable all students to

- create and use representations to organize, record, and communicate mathematical ideas;

- select, apply, and translate among mathematical representations to solve problems; 
- use representations to model and interpret physical, social, and mathematical phenomena." (NCTM, 2000, p. 67).

Many researchers (e.g., Baker, et al., 2000; Borji, Alamolhodaei, \& Radmehr, 2018; Dreher \& Kuntze, 2015; Goldin \& Shteingold, 2001; Kendal \& Stacey, 2003; Özmantar et al., 2010; Pape \& Tchoshanov, 2001; Ronda, 2015) have explored the importance of representations in developing mathematical understanding. Goldin and Shteingold (2001) explained that representations (algebraic, graphical, numerical, and textual) are important for the learning of mathematical concepts because of the coherent structure contained within each representation. This coherent structure can constrain or shape learning. Furthermore, different representations of a mathematical concept emphasize different aspects of that concept, and so the deeper understanding of the concept comes from the full range of representations. Kaput (1992) highlighted that all aspects of a complex concept cannot be adequately represented within a single representation, and hence require different representations for their full expression.

When one talks about representations, it is important and necessary to distinguish between external and internal representations. Internal representations are the mental representations which one has at a personal level of mental understanding, whereas external representations are symbols, graphs, numbers, words, diagrams, etc. (Davis, 1984; Pape \& Tchoshanov, 2001). For a particular mathematical concept, both the external and internal representations may be similar, but not necessarily the same, because the internal ones are always personally derived. Shulman (1986) considered external representations to be part of teachers' pedagogical content knowledge. He defined the external representations as "...analogies, illustrations, examples, explanations and demonstrations - in a word, the ways of representing and formulating the subject that make it comprehensible to others" (Shulman, 1986, p. 9). Ball, Thames and Phelps (2008) also identified external representations as being part of the specialized content knowledge of mathematics unique to teaching. External representations also play an important role in the understanding of mathematics by students: “An important educational goal is for students to learn to use multiple forms of representation in communicating with one another" (Greeno, \& Hall, 1997, p. 363). Researchers have highlighted the role that external representations play in connecting the abstract mathematics to the concrete experiences of students (Davis, 1984; Duval, 1999; Fennema, \& Franke, 1992; Post, \& Cramer, 1989). For the purposes of teaching mathematics, teachers should be concerned with external representations of mathematical concepts, which may help students to develop powerful and flexible ways of working with these concepts (Barmby, Bilsborough, Harries, \& Higgins, 2009).

Representations of mathematical concepts have an important impact on both in facilitating mathematics instructors' understanding of pedagogical processes which, in turn, are involved in improving students' understanding and in helping students understand to-be-learned concepts (Baker, et al., 2000; Dreher \& Kuntze, 2015; Kendal \& Stacey, 2003; Özmantar et al., 2010; Pape \& Tchoshanov, 2001; Park, 2016; Ronda, 2015). Teachers need to be able to teach a mathematical concept with a variety of representations as there is "no single most powerful form of representation" (Shulman, 1986, p. 9). Multiple representations can be designed in order to highlight particular properties and constrain interpretation of a mathematical concept (Ainsworth, 1999; Kaput, 1992). Furthermore, multiple representations play an important role in the development of students' mathematical learning: "They can be considered as useful tools for constructing understanding and for communicating information and understanding" (Greeno, \& Hall, 1997, p. 362). Wood (1999) explained that conceptual understanding of a mathematical concept rests on a system of multiple representations. Lesh, Landau, and Hamilton (1983) stated that a learner understands a mathematical idea conceptually if he or she could move or translate between multiple representations.

\section{The UEE in Spain}

"Selectividad" is the popular name given to the Spanish university access tests, a written test taken by students after secondary school, necessary to get into public universities in Spain. Students usually take six 90 minutes written exams over normally four or five days in June or September. In Spain, the national government establishes the basic characteristics of the UEE (in Spanish, Evaluación del Bachillerato para el Acceso a la Universidad, EBAU); but the local administrations of each autonomous community, coordinated with the local universities and secondary schools, are responsible for designing the exams and guarantee that their content is in accordance with the baccalaureate curriculum. (LOE 2/2006, de 3 de mayo; RD 1892/2008, de 14 de noviembre; RD 558/2010, de 7 de mayo; RD 310/2016, de 29 de julio; Orden ECD/42/2018, de 25 de enero).

The aim of these exams is to valuate students' capacity to start the University studies by assessing their knowledge of the baccalaureate subjects. There are two moments in a year when the UEE can be taken, in June or in September. The classes of the second course of baccalaureate end in May. If the students have passed all the subjects of their baccalaureate program, they can take the UEE in June. Otherwise, they have another opportunity to pass the subjects that they have failed at the beginning of September. If they pass the exams then, they can take the UEE in September. Most of the students that start a degree have passed the UEE (National Statistics Institute, 2012). However, there are other ways to enter University (for instance, the entrance exams for people older than 25 
that have not studied baccalaureate) that will not be discussed here. Also, private universities have their own tests to enter them.

The UEE has changed over time, in the following lines we present a general description of its main characteristics currently (LOE 2/2006, de 3 de mayo; RD 1892/2008, de 14 de noviembre; RD 558/2010, de 7 de mayo; RD 310/2016, de 29 de julio; Orden ECD/42/2018, de 25 de enero). Nowadays, the UEE is divided into two phases: the general phase, which is compulsory for any student; and the specific phase, which is optional. In the general phase, students have to take the exams on 4 main subjects: Spanish, English (or the first foreign language), History, and a specialization subject (Mathematics II, Mathematics applied to Social Science, Latin or Art Foundations, depending on the baccalaureate program that students have taken). In the case of bilingual autonomous communities, the other official language (Catalan, Basque or Galician) is also included in the general phase. In the specific phase, students can choose up to four optional specialization subjects. There are several national baccalaureate programs: technical and scientific program, social scientific program, humanistic program, artistic program, etc. The specialization subjects are those that vary from one program to another. For example, not all the baccalaureate programs include Mathematics. In addition, there are two different subjects: Mathematics applied to Social Sciences, it corresponds to the social scientific program; and Mathematics II, studied in the technical and scientific program.

The UEE qualification is combined with the baccalaureate qualification in order to get the final grade. The first part of the final grade (out of 10 points) is calculated as follows: the average grade of baccalaureate (out of 10 points) makes the $60 \%$; and the average grade of the general phase of the UEE (out of 10 points) makes the $40 \%$. Then, if the student had some exams in the specific phase, the two best results (over 10 points) are multiplied by $0^{\prime} 1$ or $0^{\prime} 2$, depending on the affinity of the subject and the university degree to which he or she wants to enter. This is the second part of the final grade (out of 4 points). These points are added to the first part of the final grade. Therefore, the maximum final grade is 14 points. Students choose several options for degrees and universities where they would like to study. They can select any Spanish university, not only those that are in the autonomous community where they did the UEE. At the same time, universities offer a number of places for each of its degrees. Then, students that choose the same option of degree and university compete with their final grades for a place in those studies.

According to the RD 310/2016, de 29 de julio, all the tests of the UEE last 90 minutes and the maximum number of questions in each test is 15. In particular, the Mathematics II test includes some contents from several mathematical fields: Algebra (vectors, matrixes, systems of equations), Calculus (properties of functions, limits, derivative and integral), Analytic Geometry (equations of lines and planes, dot and cross products), and Probability (calculus of probability, binomial and normal distributions). Usually one or two multi-part questions are related to the derivative and the integral (LOE 2/2006, de 3 de mayo; RD 1892/2008, de 14 de noviembre; RD 558/2010, de 7 de mayo; RD 310/2016, de 29 de julio; Orden ECD/42/2018, de 25 de enero). All the questions in the Mathematics II test are open questions and not only the final result is evaluated, the procedure to obtain the answer is considered as well. Students have to choose between two options of the test. Each option includes between 3 and 6 multi-part questions and in some regions students can also choose between the questions of the same option. For example, in Cataluña the test of the last year, 2017-2018, had 6 questions in each option and students had to choose 5 questions from the same option to answer them. Students can carry a scientific, non-graphic, non-programmable calculator for Mathematics II.

\section{The UEE in Iran}

The Iranian University Entrance Exam, known as Konkour, is a multiple choice test used as one of the means to gain admission to universities in Iran. In June each year, high school graduates in Iran take this exam seeking a place in one of the public universities (National Organization of Educational Testing, 2009). The competition is fierce and the exam content is rigorous, since top universities places are limited. Public universities are only able to accept a few percent of all applicants. The exam is so stringent that students in the three main groups of mathematical sciences, experimental sciences, and human sciences and two other groups of arts and foreign languages normally spend a whole year preparing for it. Those who fail are allowed to repeat the exam in subsequent years until they pass it. Students take a 4.5-hour multiple-choice exam over the course of one day in June. The exam covers common subjects (e.g., Persian language and literature, religion and life, English and Arabic languages) and specific subjects, depending on the field (for example, for mathematical and technical sciences it consists of Mathematics, Physics and Chemistry) which are taught in Iranian high schools (National Organization of Educational Testing, 2009; Research and Educational Planning Organization, 2013). The organizers of the UEE in Iran have considered using a "negative score system" to prevent students from answering randomly. In this case, a "negative score system" means that every three wrong answers will eliminate one of the correct answers. The percentage grade of the student's performance in each subject is calculated using the following formula: 
$\underline{((3 * \text { The number of correct answers })-(\text { The number of wrong answers }))}$

$3 *$ Total number of questions

The National Organization of Educational Testing has been established by the Iranian Ministry of Science, Research, and Technology to oversee all aspects of the exam. As the number of applicants to higher education increased and the universities and institutions related to higher education expanded, it was necessary to found a larger organization with specific tasks for the student selection, therefore the National Organization of Educational Testing is established to hold all the entrance exams to universities and higher educational institutions (National Organization of Educational Testing, 2009; Research and Educational Planning Organization, 2013).

In the Iranian UEE for all groups/fields, especially for the group of mathematical and technical sciences, mathematics is one of the most important and essential subjects. In the UEE for mathematical and technical sciences, Mathematics has 55 questions as four options choice test. 85 minutes are considered for answering the mathematics questions. Questions include several topics such as calculus, geometry, analytic geometry and linear algebra, discrete mathematics, statistics and modeling, algebra and probability. Usually among 55 mathematics questions, 10-13 questions are related to the derivative and the integral (Research and Educational Planning Organization, 2013).

Finally, student scores are calculated in all common and specific (elective) subjects. A grade and rank are assigned to his/her exam. In the final selection, $80 \%$ would be assigned to the student's exam grade and $20 \%$ would be assigned to the student's averages in some subjects of the last two years of high school. Based on the final score students earn, they have the opportunity to choose several field codes, by field code we mean a field in a university. The better student score, the higher the chance of admission to the popular universities.

\section{The Importance of the Derivative and the Integral}

Usually students learn the derivative and the integral as concepts for the first time in the high school. University students learn these concepts in calculus courses at a higher level. In addition to calculus, these two concepts are used in many other mathematical subjects such as differential equations, mathematical engineering, etc. Many other fields, including engineering, economics, chemistry, physics, etc., use these concepts in various applications.

Mathematical questions related to derivatives can be presented in various representations (algebraic, graphical, numerical, and explanations with words) (Stewart, 2010). Questions related to the algebraic representation of the derivative are usually in the form of finding the derivative of an algebraic function. The questions related to the graphical representation of the derivative are usually presented in the form of sketching the graph of the derivative function from the graph of an initial function. Questions related to the numerical representations of the derivative can be presented in terms of finding the value of the derivative at a point via the values of a function that are given at points around that point. Derivative questions in relation to the explanations with words are usually presented as the application of the derivative in real world uses and optimization problems. These cases are just samples of the derivative questions from each representation. More examples are possible for any representation. Understanding and solving the derivative-related questions in their various representations and the translations between these representations is one of the challenges faced by calculus students (Badillo, Azcárate, \& Font, 2011).

Similar to derivatives, questions related to integrals can also be presented in various representations (Stewart, 2010). Integral questions presented in algebraic representations are in the form of finding the integral of an algebraic function. Graphical representations of integral questions can be designed in the form of calculating the area under a graph. Numerical representations of the integral questions are presented as numerical data in the form of inputoutput (usually in a table). These questions, for example, can ask students to estimate the distance traveled by a car using the Midpoint Rule via a table of the velocities of the car, which are read from its speedometer at regular intervals. Integral questions in relation to the explanations with words are usually being presented as the application of the integral in real world uses such as its application to physics and engineering (e.g., force due to water pressure and centers of mass). These are just samples of the integral questions from each representation. A large number of mathematical examples regarding the integral concept are possible for its different representations.

Traditional teachings and exams of calculus focus on the algebraic representation of calculus concepts (e.g., derivatives and integrals) more than in other types of representations (Baker et al., 2000; Fuentealba, et al., 2017). A number of students have difficulties with the graphical and numerical representations of calculus concepts and the applications of these concepts in real-world uses, which can be considered to be the representations using explanations with words (Badillo et al., 2011). A growing body of research has explored students' understanding of different representations of a mathematical concept as well as the importance and necessity of representations in instructors' teaching, and in mathematics textbooks (Dreher \& Kuntze, 2015; Goldin \& Shteingold, 2001; Kendal \& Stacey, 2003; Özmantar et al., 2010; Pape \& Tchoshanov, 2001; Park, 2016; Ronda, 2015). None of these research studies have analyzed mathematics questions of the UEE from the point of view of representations. 


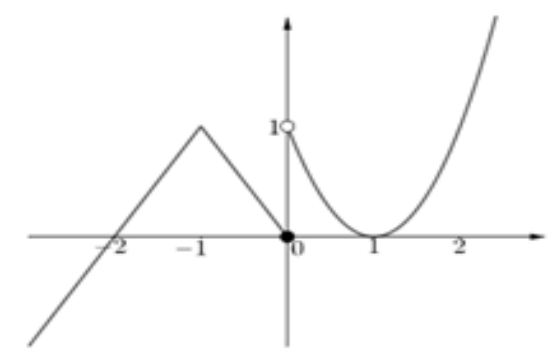

Figure 1. The graph of the function $f$

Table 1. Values of the function $\mathrm{y}=\mathrm{g}(\mathrm{x})$

\begin{tabular}{cccccccc}
\hline$x$ & 1.9 & 1.99 & 1.999 & $\ldots 2 \ldots$ & 2.0001 & 2.001 & 2.1 \\
\hline$g(x)$ & 3.61 & 3.9601 & 3.996001 & $\ldots 4 \ldots$ & 4.00040001 & 4.004001 & 4.41 \\
\hline
\end{tabular}

\section{METHOD}

In this study, the mathematical questions related to the derivative and the integral of the last five years (from the academic year 2013-2014 to 2017-2018) of the UEE in Spain ${ }^{1}$ and Iran were analyzed from the point of view of representations (algebraic, graphical, numerical and explanations with words). First, all the mathematical questions of the last five years of the UEE in these two countries were carefully studied, and then the questions related to the derivative and the integral were separated.

Then derivative and integral questions were categorized based on the type of representations that there were as the input information of the question. Four types of representations were considered: Algebraic, graphical, numerical and explanations with words. Based on the framework below, the questions were categorized.

The question would be placed in the category of the algebraic representation if the input information was given as algebraic functions, equations or expressions. A sample question of this category is given below (from the UEE in Spain).

$$
\text { If } f(x)=\left\{\begin{array}{c}
8 e^{2 x-4} x \leq 2 \\
\frac{x^{3}-4 x}{x-2} x>2
\end{array}, \text { evaluate } \int_{0}^{2} f(x) d x\right.
$$

The question would be placed in the category of the graphical representation if the input information was given as graphs of functions, or as diagrams. A sample question of this category is given below (from the UEE in Spain).

The graph of the function $f$ is shown in Figure 1, find the value of $\int_{-2}^{0} f(x) d x$.

The question would be placed in the category of the numerical representation if the input information was given as a table of numerical values or functions with numerical input and output. A sample question of this category designed by the authors is given below.

Use the values of the continuous function $g(x)$ given in Table 1 , to approximate $g^{\prime}(2)$.

The question would be placed in the category of the explanations with words if the input information was given as explanations and descriptions in the form of words. Usually questions related to the application of derivatives and integrals in the real world were placed in this category. A sample question of this category is given below (from the UEE in Iran).

The volume of a sphere increases with a constant rate 3 cubic centimeter per second. At a moment when the diameter of the sphere is 8 centimeter, what is the rate of change of the sphere surface (square centimeter per second)?

a) 1.2 b) 1.25 c) 1.5 d) 1.6

Since the input information of some questions might include more than one representation, categories for questions with combined representations were also considered. For example, a question would be placed in the algebraic-graphical category if the input information in the question was presented in both graphical and algebraic representations. A sample question of this category is given below (from the UEE in Iran).

Figure 2 is a part of the graph of the function $y=\frac{1}{2}+2 \cos m x$. Find the value of the function at the point $x=\frac{16 \pi}{3}$.

a) $\frac{-1}{2}$ b) $\frac{1}{2}$ c) 1 d) zero 


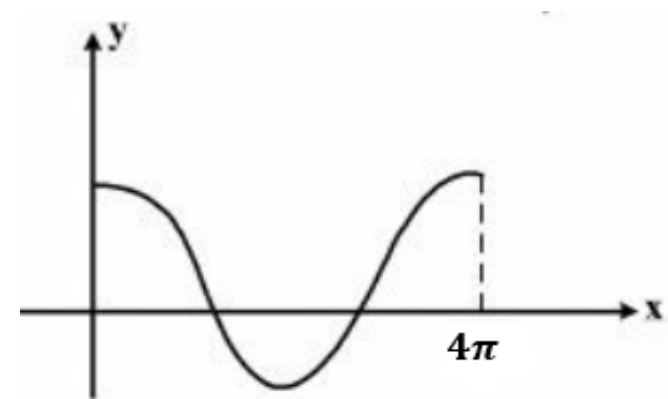

Figure 2. A part of the graph of $y=\frac{1}{2}+2 \cos m x$

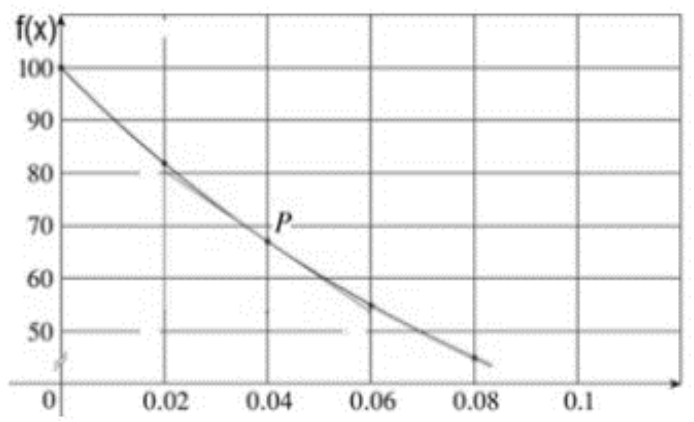

Figure 3. The graph of the function $f(x)$

Table 2. The values of the function $f(x)$

\begin{tabular}{ccccccc}
\hline$x$ & 0 & 0.02 & 0.04 & 0.06 & 0.08 & 0.10 \\
\hline$f(x)$ & 100 & 81.87 & 67.03 & 54.88 & 44.93 & 36.79 \\
\hline
\end{tabular}

A question would be placed in the category of 'explanations with words-algebraic' if the input information in the question was presented in both explanations in the form of words and algebraic functions, equations or expressions. A sample question of this category from the UEE in Spain is given below.

Consider $f(x)$ be a twice-derivable function. Knowing that the point $x=-2$ is an inflection point of the graph of $f$ and at this point $(x=-2)$ the line $y=16 x+16$ is tangent to the graph of $f$. Determine values $f(-2), f^{\prime}(-2)$ and $f^{\prime \prime}(-2)$.

A question would be placed in the graphical-numerical category if the input information in the question was presented in both graphs of functions and a table of numerical data. A sample question of this category designed by the authors is given below.

Using the graph of the function $f(x)$ (Figure 3) and Table 2, approximate $f^{\prime}(0.04)$.

The other combined categories (e.g., algebraic-numerical, graphical-explanations with words, etc.) are defined in the same way. To confirm our representational framework and categorize the questions, group meetings were held with two professors in Mathematics and two professors in Mathematics Education who had more than 15 years of experience in teaching calculus in the high school and the university.

\section{RESULTS}

Mathematics questions on the UEE related to derivatives and integrals in both Spain and Iran were analyzed from the representations point of view, and each question was sorted into a category. In this section, the results of the categorization are presented.

\section{Representations in the Mathematics Questions of the UEE in Spain}

In the case of the UEE in Spain, 189 questions were examined, 21 and 19 of which were related to the derivative and the integral, respectively. The rest of the questions were related to other mathematical topics (e.g., vectors, matrixes, systems of equations, equations of lines and planes, dot and cross products, and probability). Among the 21 questions of the derivative, the dispersion of the representations is given in Table 3. 
Table 3. Distribution of the representations in the derivative questions of the UEE in Spain The representation presented as the input

\begin{tabular}{lccc}
$\begin{array}{l}\text { The representation presented as the input } \\
\text { information in the question }\end{array}$ & Algebraic & Graphical & $\begin{array}{c}\text { Explanations with words- } \\
\text { algebraic }\end{array}$ \\
\hline Number of questions & 17 & 2 & 2 \\
\hline
\end{tabular}

Table 4. Distribution of the representations in the integral questions of the UEE in Spain

\begin{tabular}{lccc}
\hline $\begin{array}{l}\text { The representation presented as the input } \\
\text { information in the question }\end{array}$ & Algebraic & Graphical & Algebraic-numerical \\
\hline Number of questions & 16 & 1 & 2 \\
\hline
\end{tabular}

Table 5. Distribution of the representations in the derivative questions of the UEE in Iran

\begin{tabular}{|c|c|c|c|c|c|}
\hline $\begin{array}{l}\text { The representation presented as the input } \\
\text { information in the question }\end{array}$ & Algebraic & Graphical & $\begin{array}{l}\text { Explanations } \\
\text { with words }\end{array}$ & $\begin{array}{l}\text { Algebraic- } \\
\text { graphical }\end{array}$ & $\begin{array}{l}\text { Algebraic- } \\
\text { numerical }\end{array}$ \\
\hline Number of questions & 25 & 1 & 3 & 7 & 1 \\
\hline
\end{tabular}

According to Table 3, it can be seen that a high percentage of questions of the UEE in Spain relate to the algebraic representation. Only 2 questions were related to graphical representation and there were no questions regarding numerical representation. In the case of the relationship between representations, there were two questions related to the combined representation of algebraic-explanations with words. There was not any question in which the relationship between other types of representation was identified.

The variety of representations for the integral questions of the UEE in Spain is presented in Table 4.

Table 4 shows that a high percentage of integral questions were related to the algebraic representation. There was only one integral question regarding graphical representation, and there was no question in which input information was given only by numerical data. In relation to the combined representations, there were two questions related to algebraic-numerical representation, and there was no question related to the relationship between the other representations.

\section{Representations in the Mathematics Questions of the UEE in Iran}

In the case of Iran, the derivative and the integral questions of the UEE for the field of mathematical sciences between 2013-2014 and 2017-2018 were examined. A total of 275 mathematics questions were investigated. 37 and 11 questions were related to the derivative and the integral respectively. The rest of the questions were related to other mathematical topics (e.g., geometry, analytic geometry and linear algebra, discrete mathematics, statistics and modeling, algebra and probability). Among the 37 questions of the derivative, the dispersion of the representations is given in Table 5 .

It can be seen from Table 5 that a high percentage of the derivative questions of the UEE in Iran presented input information only by the algebraic representation. There was only one question of the derivative that provided the input information as a graphical representation, and there was no question of the derivative that gave input data only via the numerical data. Regarding the relationship between the representations, 7 questions provided input information as algebraic-graphical data. Only one question was related to the relationship between the algebraic and numerical representations and there was no question in which input information was presented as a combination of other representations.

The results of the analysis of the questions showed that all 11 questions concerning the integral were presented with an algebraic representation.

\section{DISCUSSION AND CONCLUSION}

A number of students in the first year of the university have fundamental difficulties in solving graphical and numerical questions related to derivatives and integrals (Borji, Font, Alamolhodaei, \& Sánchez, 2018; Baker et al, 2000; Cooley, Trigueros, \& Baker, 2007). One of the reasons may be that they did not well understand these concepts in different representations during the high school. Students in the last years of the high school get involved with the UEE. They aim to pass the UEE in order to enter to the university (Farrokhi-Khajeh-Pasha, et al., 2012; Kim \& Dembo, 2000; Koçkar \& Gençöz, 2004; Konečný, et al., 2012; Kusayanagi, 2013; Zhang, 2016). In some cases, admission to top universities remains a means of achieving elevated status in a society in which education is a major determinant of class mobility. Graduates of such universities have a better chance of securing increasingly limited jobs in professions such as medicine, engineering, and law (Kusayanagi, 2013).

Students learn math concepts in some way to solve the mathematics questions of the UEE. Mathematics teachers also teach their students how to solve mathematics questions of the UEE. Despite the importance and effect 
of the UEE on the teaching approach of mathematics teacher and students' mathematical learning, research about the UEE is very limited in mathematics education. In the present study, the UEE and the kind of its mathematics questions are considered as one of the effective factors on the teaching and learning of mathematics by teachers and their students. The mathematics questions about derivatives and integrals of the UEE in Spain and Iran between 2013-2014 and 2017-2018 were analyzed from the point of view of representations (i.e., algebraic, graphical, numerical and explanations with words). The results showed that a high percentage of the questions was presented in an algebraic representation, and a very low percentage was related to other representations and the relationship between the representations.

This high number of algebraic mathematics questions in the UEE causes students in the last years of high school to focus more on the algebraic representation of calculus concepts (e.g., derivative and integral) and less attention to the other representations (graphical, numerical, explanation with words) and the translation between these representations. For this reason, students in the first year of the university may have fundamental difficulties in solving non-algebraic derivatives and integrals' questions. Students in the first year of the university face difficulties in solving the calculus questions where input information is given only through graphical or numerical representations (Borji, Font, Alamolhodaei, \& Sánchez, 2018; Baker et al, 2000; Cooley et al., 2007). Many research have recommended that, in order to achieve a conceptual understanding of a mathematical concept, it is better to start learning that concept in its various representations and connections between them (Baker et al., 2000; Borji, Alamolhodaei, \& Radmehr, 2018; Dreher \& Kuntze, 2015; Goldin \& Shteingold, 2001; Kendal \& Stacey, 2003; Özmantar et al., 2010; Pape \& Tchoshanov, 2001; Ronda, 2015). Students usually learn derivative and integral concepts in high school for the first time. To achieve a conceptual understanding of these concepts, it is recommended that students at the high school level are able to understand and interpret them in their different representations. Therefore, the mathematics questions of the UEE should not be such that they force students to concentrate more on algebraic representations of concepts.

To answer mathematics questions of the UEE in Spain, students write the whole process of solving in the answer sheet. For each of the students' answers, they are given a suitable score (Orden ECD/42/2018, de 25 de enero). The UEE in Iran is a multiple choice test. Iranian students have to choose one of the four options for each question and mark it on the answer sheet (National Organization of Educational Testing, 2009; Research and Educational Planning Organization, 2013). This kind of exam may cause a student to choose one of the four options by randomly (by chance) for a question, even without solving the question. The process of solving and how students reach the final solution are not being considered by the Iranian examiners. Only the option that the student chooses is being considered. This allows students to explore the answer, through shortcut and non-conceptual solutions, and mathematical techniques. This kind of exam (i.e., four options choice test) and how it is being evaluated also affects the teaching of mathematics teachers who prepare their students for the UEE. It causes mathematics teachers to teach shortcuts and techniques to their students in order to find the final answer rather than teach mathematics conceptually.

The designers of the mathematics questions of the UEEs should be aware of the importance of representations and relationships between them when designing the derivative and the integral questions. They should design questions that relate to the different types of representations and their combinations. In other words, it is suggested that there be a balance in the number of math problems using each of the different representations in the mathematics questions of the UEE. It is also recommended that the mathematics questions of the UEE are structured so that students can write the process of their solving on the answer sheet. In the calculation of students' scores, the students' hand-written answers should be considered. The UEE in this way (i.e., diversity in mathematical representations and open response questions) also affects the teaching of mathematics teachers, who are preparing their students for the UEE; encouraging them to focus on the importance of different representations and translations between them when teaching mathematical concepts. Since students usually solve the questions of previous years of the UEE to prepare themselves for this exam, students, by seeing mathematical questions in various representations, try to learn a mathematical concept in different representations in order to be able to answer a number of questions with different representations.

This research analyzed the UEE in two countries, Spain and Iran. Considering the importance of the UEE and its effect on both the teaching of mathematics teachers and on students' learning, it is recommended that similar research be conducted in the case of other countries. In the current study, the importance of representations related to the derivative and the integral in mathematics questions of the UEE was studied. It is recommended that questions about other mathematics topics that are included in the UEE also be examined from the perspective of representations. In Iran, the students' textbooks are designed in accordance with the official curriculum. Then, another possibility is designing Mathematics questions of the UEE based on the high school's mathematics textbooks. It is recommended that researchers explore how much similarity there is between the mathematics questions of the UEE and the mathematics questions of the high school textbooks, and to what extent the designers 
of mathematics questions of the UEE have considered the goals of the designers and planners of the mathematics textbooks and curriculum.

\section{REFERENCES}

Ainsworth, S. (1999). The Functions of Multiple Representations. Computers E Education, 33(2), 131-152, https:/ / doi.org/10.1016/S0360-1315(99)00029-9

Badillo, E., Azcárate, C., \& Font, V. (2011). Analysis of Mathematics teachers' level of understanding of the objects $f^{\prime}(a)$ and $f^{\prime}(x)$. Enseñanza de las ciencias, 29(2), 191-206. https:/ / doi.org/10.5565/rev/ec/v29n2.546

Baker, B., Cooley, L., \& Trigueros, M. (2000). A calculus graphing schema. Journal for Research in Mathematics Education, 31(5), 557-578. https:/ / doi.org/10.2307/749887

Ball, D. L., Thames, M. H., \& Phelps, G. (2008). Content knowledge for teaching: What makes it special? Journal of Teacher Education, 59(5), 389-407. https:/ / doi.org/10.1177/0022487108324554

Barmby, P., Bilsborough, L., Harries, T. \& Higgins, S. (2009). Primary Mathematics: teaching for understanding. Berkshire: Open University Press.

Beltrán-Pellicer, P., Godino, J. D. \& Giacomone, B. (2018). Elaboration of Specific Didactical Suitability Criteria in Probability: Application for Reflection on the Teaching Practice. Bolema, 32(61), 526-548. https://doi.org/10.1590/1980-4415v32n61a11

Bolden, D. S., Barmby, P. W., \& Harries, A. V. (2013). A representational approach to developing primary ITT students' confidence in their mathematics. International Journal of Mathematical Education in Science and Technology, 44(1), 70-83. https:/ / doi.org/10.1080/0020739X.2012.690899

Borji, V., Alamolhodaei, H., \& Radmehr, F. (2018). Application of the APOS-ACE Theory to improve Students' Graphical Understanding of Derivative. EURASIA Journal of Mathematics, Science and Technology Education, 14(7), 2947-2967. https:/ / doi.org/10.29333/ ejmste/91451

Borji, V., Font, V., Alamolhodaei, H., \& Sánchez, A. (2018). Application of the Complementarities of Two Theories, APOS and OSA, for the Analysis of the University Students' Understanding on the Graph of the Function and its Derivative. EURASIA Journal of Mathematics, Science and Technology Education, 14(6), 2301-2315. https://doi.org/10.29333/ejmste/89514

Breda, A., Font, V., \& Pino-Fan, L. (2018). Evaluative and normative criteria in Didactics of Mathematics: the case of didactical suitability construct. Bolema, 32(60), 255-278. https:/ / doi.org/10.1590/1980-4415v32n60a13

Breda, A., Pino-Fan, L. R., \& Font, V. (2017). Meta didactic-mathematical knowledge of teachers: criteria for the reflection and assessment on teaching practice. EURASIA Journal of Mathematics, Science and Technology Education, 13(6), 1893-1918. https:/ / doi.org/10.12973/eurasia.2017.01207a

Bruner, J. S. \& Kenney, H. J. (1965). Representation and mathematics learning. The Society for Research in Child Development (monographs), 30(1), 50-59. https:/ / doi.org/10.2307/1165708

Cooley, L., Trigueros, M., \& Baker B. (2007). Schema thematization: A theoretical framework and an example. Journal for Research in Mathematics Education, 38(4), 370-392. https:/ / doi.org/10.2307/30034879

Davis, R. B. (1984). Learning Mathematics: The Cognitive Approach to Mathematics Education. London: Croom Helm.

Dominguez, A., Barniol, P., \& Zavala, G. (2017). Test of Understanding Graphs in Calculus: Test of Students' Interpretation of Calculus Graphs. EURASIA Journal of Mathematics, Science and Technology Education, 13(10), 6507-6531. https:/ / doi.org/10.12973/ ejmste/78085

Dreher, A., \& Kuntze, S. (2015). Teachers' professional knowledge and noticing: The case of multiple representations in the mathematics classroom. Educational Studies in Mathematics, 88(1), 89-114. https:/ / doi.org/10.1007/s10649-014-9577-8

Duval, R. (1999). Representation, vision and visualization: Cognitive functions in mathematical thinking: Basic issues for learning. In F. Hitt \& M. Santos (Eds.), Proceedings of the Twenty First Annual Meeting of the North American Chapter of the International Group for the Psychology of Mathematics Education, Morelos, México, Vol. I, pp. 3-26.

Farrokhi-Khajeh-Pasha, Y., Nedjat, S., Mohammadi, A., Malakan Rad, E., Majdzadeh, R., Monajemi, F., Jamali, E., \& Yazdani, S. (2012). The validity of Iran's national university entrance examination (Konkoor) for predicting medical students' academic performance. BMC Medical Education, 12(60), 60, https:/ / doi.org/10.1186/1472-6920-12-60

Fennema, E., \& Franke, M. L. (1992). Teachers' knowledge and its impact. In D. A. Grouws (Ed.), Handbook of research on mathematics teaching and learning: A project of the National Council of Teachers of Mathematics (pp. 147-164). New York, NY, England: Macmillan Publishing Co, Inc. 
Fuentealba, C., Sánchez-Matamoros, G., Badillo, E., \& Trigueros, M. (2017). Thematization of derivative schema in university students: Nuances in constructing relations between a function's successive derivatives. International journal of mathematical education in science and technology, 48(3), 374-392. https:/ / doi.org/10.1080/0020739X.2016.1248508

Goldin, G., \& Shteingold, N. (2001). Systems of representation and the development of mathematical concepts. In A. A. Cuoco (Ed.), The roles of representation in school mathematics, NCTM 2001 Yearbook (pp. 1-23). Reston, VA: National Council of Teachers of Mathematics.

Greeno, J. G., \& Hall, R. P. (1997). Practicing Representation: Learning with and about representational forms. Phi Delta Kappan, 78(5), 361-368. https:/ / doi.org/10.2307/20405797

Hardy, N. (2009). Students' perceptions of institutional practices: the case of limits of functions in college level Calculus courses. Educational Studies in Mathematics, 72(3), 341-358, https://doi.org/10.1007/s10649-0099199-8

Kaput, J. (1992). Technology and mathematics education. In D.A. Grouws (Ed.) Handbook of research on mathematics and teaching and learning (pp. 515-556). New York, NY: Macmillan Publishing Company.

Kendal, M., \& Stacey, K. (2003). Tracing learning of three representations with the Differentiation Competency Framework. Mathematics Education Research Journal, 15(1), 22-41. https:/ / doi.org/10.1007/BF03217367

Kim, C. W., \& Dembo M. H. (2000). Social- cognitive factors influencing success on college entrance exams in South Korea. Social Psychology of Education, 4(2), 95-115, https:/ / doi.org/10.1023/ A:1009659529840

Koçkar, A. İ., \& Gençöz, T. (2004). Personality, Social Support, and Anxiety among Adolescents Preparing for University Entrance Examinations in Turkey. Current Psychology, 23(2), 138-146. https:/ / doi.org/10.1007/BF02903074

Konečný, T., Basl, J., Mysliveček, J., \& Simonová, N. (2012). Alternative models of entrance exams and access to higher education: The case of the Czech Republic. Higher Education, 63(2), 219-235. https:/ / doi:10.1007/s10734-011-9433-z

Kusayanagi, C. (2013). Constructing and Understanding an Incident as a Social Problem: A Case Study of University Entrance Exam Cheating in Japan. Human Studies, 36(1), 133-148. https:/ / doi.org/10.1007/s10746-013-92562

Lesh, R., Landau, M., \& Hamilton, E. (1983). Conceptual models and applied mathematical problem-solving research. In R. Lesh and M. Landau (Eds.), Acquisition of mathematics concepts and processes (pp. 263-343). Orlando, FL: Academic Press.

Ley Orgánica 2/2006, de 3 de mayo, de Educación. Boletín Oficial del Estado, 4 de mayo de 2006, num. 106, pp. 1715817207. Retrieved from https:/ / www.boe.es/boe/dias/2006/05/04/pdfs / A17158-17207.pdf

Mao, Y., White, T., Sadler, P. M., \& Sonnert, G. (2017). The association of precollege use of calculators with student performance in college calculus. Educational Studies in Mathematics, 94(1), 69-83, https://doi.org/10.1007/s10649-016-9714-7

McAteer, M. (2012). Improving Primary Mathematics Teaching and Learning. England: Open University Press.

National Council of Teachers of Mathematics. (2000). Principles and standards for school mathematics. NCTM, Reston VA.

National Organization of Educational Testing. (n.d). Retrieved from http://www.sanjesh.org/en/aboutus.aspx\#a3

National Statistics Institute (2012). Boletín informativo del Instituto Nacional de Estadística. Panorámica de la educación universitaria. Retrieved from https://www.ine.es/ss/Satellite?L=es_ES\&c=INECifrasINE_C\&cid= $1259940012843 \& \mathrm{p}=1254735116567 \&$ pagename=ProductosYServicios\%2FPYSLayout

Orden ECD/42/2018, de 25 de enero, por la que se determinan las características, el diseño y el contenido de la evaluación de Bachillerato para el acceso a la Universidad, las fechas máximas de realización y de resolución de los procedimientos de revisión de las calificaciones obtenidas, para el curso 2017/2018. Boletín Oficial del Estado, 26 de enero de 2018, num. 23, pp. 9757-9789. Retrieved from https:/ / www.boe.es/boe/dias/2018/01/26/pdfs/BOE-A-2018-984.pdf

Özmantar M. F., Akkoç, H., Bingölbali, E., Demir, S., \& Ergene B. (2010). Pre-Service Mathematics Teachers' Use of Multiple Representations in Technology-Rich Environments. Eurasia Journal of Mathematics, Science $\mathcal{E}$ Technology Education, 6(1), 19-36. https://doi.org/10.12973/ejmste/75224

Pape, S. J., \& Tchoshanov, M. (2001). The role of representation(s) in developing mathematical understanding. Theory into Practice, 40(2), 118-127. https:/ / doi.org/10.1207/s15430421tip4002_6 
Park, J. (2016). Communicational approach to study textbook discourse on the derivative. Educational Studies in Mathematics, 91(3), 395-421. https:/ / doi.org/10.1007/s10649-015-9655-6

Post, T., \& Cramer, K. A. (1989). Knowledge, representation, and quantitative thinking: A special AACTE publication. In M. Reynolds, \& W. Gardner (Eds.), Knowledge base for beginning teachers: A special AACTE publication (pp. 221-232). Oxford, UK: Pergamon Press.

Real Decreto 1892/2008, de 14 de noviembre, por el que se regulan las condiciones para el acceso a las enseñanzas universitarias oficiales de grado y los procedimientos de admisión a las universidades públicas españolas. Boletín Oficial del Estado, 24 de noviembre de 2008, num. 283, pp. 46932-46946. Retrieved from https:/ / www.boe.es/boe/dias/2008/11/24/pdfs/A46932-46946.pdf

Real Decreto 558/2010, de 7 de mayo, por el que se modifica el Real Decreto 1892/2008, de 14 de noviembre, por el que se regulan las condiciones para el acceso a las enseñanzas universitarias oficiales de grado y los procedimientos de admisión a las universidades públicas españolas. Boletín Oficial del Estado, 8 de mayo de 2010, num. 113, pp. 40784-40788. Retrieved from https://www.boe.es/boe/dias/2010/05/08/pdfs/BOEA-2010-7330.pdf

Real Decreto 310/2016, de 29 de julio, por el que se regulan las evaluaciones finales de Educación Secundaria Obligatoria y de Bachillerato. Boletín Oficial del Estado, 30 de julio de 2016, num. 183, pp. 53049-53065. Retrieved from https:/ /www.boe.es/boe/dias/2016/07/30/pdfs/BOE-A-2016-7337.pdf

Research and Educational Planning Organization. (2013). Secretariat of designing and producing the mathematics curriculum of Islamic Republic of Iran [In Persian].

Ronda, E. (2015). Growth points in linking representations of function: a research-based framework. Educational Studies in Mathematics, 90(3), 303-319. https:/ / doi.org/10.1007/s10649-015-9631-1

Sahin, Z., Erbas, A. K., \& Yenmez, A. A. (2015). Relational Understanding of the Derivative Concept through Mathematical Modeling: A Case Study. EURASIA Journal of Mathematics, Science \& Technology Education, 11(1), 177-188. https:/ / doi.org/10.12973/eurasia.2015.1149a

Shulman, L. S. (1986). Those Who Understand: Knowledge Growth in Teaching. Educational Researcher, 15(2), 4-14. https://doi.org/10.3102/0013189X015002004

Spangler, D. B. (2010). Strategies for teaching whole number computation: using error analysis for intervention and assessment. Thousand Oaks, CA: Corwin Press.

Stewart, J. (2010). Calculus, 7th Edition. Brooks/Cole Cengage Learning, Mason.

Wood, D. (1999). Editorial: Representing, learning and understanding. Computers E Education, 33(2-3), 83-90. https:/ / doi.org/10.1016/S0360-1315(99)00026-3

Zhang, Y. (2016). National College Entrance Exam in China: Perspectives on Education Quality and Equity. The Netherlands: Springer Briefs in Education.

\section{http://www.ejmste.com}

